\section{LA APORTACIÓN DE JOSÉ JIMÉNEZ LOZANO AL NACIMIENTO DE LAS EDADES DEL HOMBRE}

\author{
María Merino Bobillo \\ Universidad de Valladolid \\ maría.merino@hmca.uva.es
}

\section{JOSE JIMÉNEZ LOZANO'S CONTRIBUTION TO THE BIRTH OF LAS EDADES DEL HOMBRE}

Cómo citar este artículo/Citation: Merino Bobillo, M. (2015). "La aportación de José Jiménez Lozano al nacimiento de Las Edades del Hombre". Arbor, 191 (772): a225. doi: http:// dx.doi.org/10.3989/arbor.2015.772n2011

Recibido: 10 junio 2014. Aceptado: 14 febrero 2015.

RESUMEN: José Jiménez Lozano desempeñó un papel esencial en el nacimiento de Las Edades del Hombre tanto por su amistad con José Velicia, su creador, como por la hondura y particularidad de sus conocimientos sobre el arte y la cultura que marcaron la personalidad del ciclo de exposiciones. Podemos documentar dicha aportación a través del rastreo de sus publicaciones anteriores al proyecto y de las entrevistas con algunas de las personas que colaboraron en su puesta en marcha. Haremos especial hincapié en un documento inédito que sirvió de presentación del mismo y en el que se descubre la mano de Jiménez Lozano. La estructura de los resultados obtenidos se relata tomando como puntos de anclaje las palabras de José Jiménez Lozano, ya sea en sus escritos, conferencias, o estudios realizados sobre él. Su escritura nos permite profundizar en las claves que han hecho de unas exposiciones un referente cultural.

PALABRAS CLAVE: José Jiménez Lozano; José Velicia; Las Edades del Hombre; patrimonio artístico; Castilla y León; exposiciones; cultura.
Copyright: (C) 2015 CSIC. Este es un artículo de acceso abierto distribuido bajo los términos de la licencia Creative Commons Attribution-Non Commercial (by-nc) Spain 3.0.

ABSTRACT: José Jiménez Lozano played an essential role in the birth of the Las Edades del Hombre (the Ages of Man) exhibition both through his friendship with José Velicia, the exhibition's creator, and his profound and detailed knowledge of the art and culture that shaped the exhibition series. This contribution can be documented by tracking his publications prior to the project and through interviews with some of the people involved in setting it up. Particular emphasis is given here to an unpublished document that served as a presentation and shows clearly Jiménez Lozano's particular style. The structure of the results is narrated taking José Jiménez Lozano's words from his writings or lectures, or studies on him as anchor points. His writing allows us to delve into the keys that have made these exhibitions a great cultural reference.

KEYWORDS: Jiménez Lozano; José Velicia; Las Edades del Hombre (the Ages of Man); cultural heritage; Castilla y León; artistic exhibition; culture. 


\section{LA GESTACIÓN DE UNA AVENTURA CULTURAL}

El alcance de las exposiciones Las Edades del Hombre y su permanencia en el tiempo no pueden entenderse sin el conocimiento de lo que fueron sus orígenes. A la altura del año 2014 se han presentado ya diecinueve ediciones. Su objeto material es de importancia capital: se trata de mostrar el caudaloso patrimonio artístico de la Iglesia Católica en el marco territorial de la Comunidad Autónoma de Castilla y León, una de las regiones más amplias de la Unión Europea, compuesta por nueve provincias que abarcan más de 94.000 kilómetros cuadrados y con un patrimonio eclesiástico superior al de otras regiones de España y sobresaliente entre las europeas. Pero Las Edades del Hombre no hubiesen sido lo que son, sino por la particular impronta de su objeto formal: el modo en el que se concibieron y en el que fueron trabajadas. Su nacimiento tiene un nombre propio, José Velicia Berzosa. Su idea creadora encontró el inapreciable apoyo de José Jiménez Lozano. En el seno de su amistad se engendró un proyecto de aprecio al arte y a la historia. Cuando ya mostró su rostro fue presentado como una iniciativa de la Iglesia en Castilla y León, apoyada por la Junta de Castilla y León, que pasó del tímido apoyo inicial a incorporarlo a su oferta cultural y convertirlo en uno de sus proyectos turístico-artísticos estrella. Las Edades del Hombre son, ante todo, la aventura de dos personas, Velicia y Jiménez Lozano, a los que se unieron un selecto grupo de gente que puso toda su ilusión en hacer realidad el sueño de aquellos. Conocer su alma exige acercarse a descubrir a las personas que la originaron, capítulo con el que se inicia este texto, para continuar con el estudio del papel jugado por el escritor.

\section{JOSÉ VELICIA: EL RETRATO DE UN HOMBRE JUSTO}

José Velicia Berzosa nació en 1931 en Traspinedo, en la provincia de Valladolid. En 1955 fue ordenado sacerdote y enviado como párroco a Olmedo, un pueblo distante 45 kilómetros de la capital y nueve de Alcazarén, donde residía la familia de José Jiménez Lozano desde 1956. La proximidad geográfica permitió su conocimiento y una amistad que permanece años después de la muerte de Velicia. Compartieron época de nacimiento, raíces rurales y aficiones. El tema de sus conversaciones giraba en torno al arte, la lectura, la música, la historia. "Una novela o un libro, una iglesita o una piedra que había visto en el campo, yendo de camino, una tertulia apasionante o una charla improvisada, un disco nuevo, era seguro que constituían para nosotros un viaje muy largo, porque, como las cerezas unas se enredan a las otras y van saliendo, así nos ocurre con todo en nuestra vida, pero de un modo muy especial en el mundo de la cultura, que en esto consiste." (Jiménez Lozano, conferencia inédita pronunciada en 2007).

En la década de los 80, en un viaje a Barcelona, visitó Thesaurus, una exposición de arte sacro que puso la semilla de lo que iba a constituir la pasión de su vida: testimoniar la belleza de la fe a través de las obras de arte diseminadas por el territorio de Castilla y León. A partir de entonces su empeño fue Las Edades del Hombre.

Era un hombre que sembraba y generaba amistades: "José Velicia, como saben muy bien todos los que le conocían, tenía el don de hacerse amigo de todo aquel con quien se encontraba, por extraño que fuese, y éste sabía que era así porque fresca e infantil como era su risa, era la vez un gran poro o puerta de sí mismo que dejaba abierta y por donde uno podía colarse y por la que sabía que se había colado. Era un don, ya digo, el de hacer amigos, y el de reír de ese modo" (Jiménez Lozano, conferencia inédita pronunciada en 2007).

Si algo llama poderosamente la atención en el estudio de cómo se hizo realidad el proyecto es la impronta tan profunda que este sacerdote dejaba entre las personas que le ayudaron. Muchos lo expresan en un libro de homenaje promovido por Jiménez Lozano que él mismo califica en el prólogo como “(...) páginas que cada cual ha sacado del cosero de su oficio y trabajo, son el ofrecimiento de un grupo de amigos a la memoria de José Velicia." (VV. AA., 2002). Sebastián Battaner, el mecenas que apoyó económicamente lo que todavía no era más que un sueño, escribe en la presentación: "Nunca imaginé lo difícil que resultaría hablar de un amigo. Jamás sospeché lo mucho que José modeló mi vida." (VV. AA., 2002). Sorprende la emoción con la que, veintitrés años después de su muerte, le recuerdan quienes trabajaron cerca de él en esos primeros años, como si su presencia fuera todavía cercana. Pablo Puente Aparicio, que compartió con él tantas y tantas horas en la preparación y en la resolución de los problemas arquitectónicos de las exposiciones, confiesa que le resulta doloroso hablar sobre ello, como si la herida de la pérdida no se hubiera aún cerrado. Así lo escribía en el libro homenaje: "Pero hoy siento la soledad y no me sirven de refugio los recuerdos. Quisiera oírle reír fuerte (...). Quisiera estar con él buscando iconografías siempre nuevas, o soñando un Cister revitalizado en Santa María de Valbuena. (Martínez Duque, 2002, p. 127). Involucraba a 
la gente en su proyecto de tal forma que este pasaba a constituir una de las prioridades del recién llegado. M. a Antonia Virgili Blanquet, catedrática de Musicología de la Universidad de Valladolid, que se convirtió en su principal apoyo para la exposición sobre la música, afirma sin ambages: "Me ha enriquecido humanamente, espiritualmente y profesionalmente como ninguna otra cosa lo ha hecho en mí" (entrevista a M. a Antonia Virgili Blanquet). Subraya cómo respetaba las aportaciones de quienes quisieron ayudarle, dándoles una gran libertad de actuación y corriendo el riesgo de verse defraudado: “O el de las famosas apologías y disculpas que acumulaba para excusar cualquier cosa en los demás, hasta un punto en que los que éramos más cercanos le hacíamos críticas o advertencias, y nos burlábamos afectuosamente de tantas confianzas que le resultaron fallidas, pero cuyas fallas a él no le marcaban y éramos nosotros los que teníamos que arrepentirnos de haber pensado mal aunque tuviéramos razón." (Jiménez Lozano, conferencia inédita pronunciada en 2007).

Junto a su capacidad de hacerse amigos, los testimonios sobre él subrayan su condición hondamente sacerdotal: "José Velicia fue una gran persona, un gran amigo y un gran creyente. De su persona recordamos, sobre todo, su profunda humanidad, su sencillez, su tolerancia, su limpieza de miras, su carcajada abierta y espontánea, su constancia y su tesón. De su amistad recordamos su cercanía, su cariño, su lealtad, su discreción, su disponibilidad, su capacidad de acogida y el apoyo que siempre ofreció a todos sus amigos. De su condición de creyente recordamos sus inquietudes, su compromiso, sus urgencias y prioridades, su esperanza, su coherencia animada, sobre todo, por su fidelidad a Jesucristo, a la Iglesia y a los hombres." (Martínez Duque, 2002, p. 139).

Castellano, nacido en un pueblo, se encontraba a gusto en ese medio: "José Velicia tuvo luego otros cargos pastorales, sin duda no tan de su gusto como el del pueblo, pero de todos modos ofreció siempre la sensación de estar en su salsa, hiciera lo que hiciera" (Martínez Duque, 2002, p. 125). Si con frecuencia se asimila al hombre de pueblo con el de poca cultura, figuras como la suya muestran la torpeza de esta simplificación, pues aquella no viene condicionada por el lugar geográfico donde residan las personas, sino por la catadura y las elecciones que hacen para alimentar su intelecto. Jiménez Lozano le define como especialmente culto: “(...) un hombre muy bien avenido, inmerso y preocupado en el mundo de la cultura como quien en él respira: singularmente en el ámbito del arte, y de la música en especial, y lector practicante de literatura" (Jiménez Lozano, conferencia inédita pronunciada en 2007). La expresión "lector practicante de literatura" utilizada por el escritor encierra un nítido significado: "Esto es, no un nómada de novedades, sino un sedentario de libros y habitante de ese universo que es lo que es un lector al que un libro puede durar medio año, o años, coleando" (Jiménez Lozano, conferencia inédita pronunciada en 2007).

El 18 de junio de 1997 moría en su casa, rodeado de familiares y de un grupo reducido de amigos que acudieron a vivir con él las últimas edades en la tierra. Tenía 66 años y dejaba un profundo legado cultural que le valió la Medalla de Oro de las Bellas Artes, concedida por el Ministerio de Cultura.

Tras el retrato de José Velicia, el fundador de Las Edades del Hombre, pasamos a dar algunas pinceladas sobre quien fue su puntal, su amigo Pepe Jiménez Lozano.

\section{JOSÉ JIMÉNEZ LOZANO}

Si José Velicia fue el visionario del proyecto, la compañía de José Jiménez Lozano fue decisiva en su profundidad y originalidad. Nacido en el año 1930 en Langa, en la provincia de Ávila, toda la familia se trasladó en 1956 en Alcazarén, un pueblo de Valladolid, distante nueve kilómetros de Olmedo, el lugar de residencia de Velicia. Tras estudiar Derecho comenzó a preparar las oposiciones a judicatura, pero el destino le reservó una salida a su inclinación humanista y a la destreza de su pluma. Comenzó a enviar artículos a El Norte de Castilla, a cuya cabeza se encontraba Miguel Delibes, quien quedó seducido por el talento de aquel joven de veintiséis años. Paulatinamente fue contando con él en los proyectos que iba poniendo en marcha en el diario vallisoletano, hasta que pudo contratarle como redactor en 1965. Dotado de una fina e inquieta inteligencia, se convirtió en punta de lanza del periódico. Se le encargaron las partes duras del mismo: la redacción de los editoriales y las notas internacionales. Años más tarde fue nombrado subdirector y los últimos años de su vida profesional, de 1992 a 1995, fue el director.

La agudeza de su pensamiento y la brillantez de su expresión literaria le hizo ser solicitado por diferentes publicaciones ya desde los años sesenta: semanarios -Destino y Vida Nueva- a los que se sumaron los periódicos-Informaciones, El Sol, El País, ABC, El Día de Valladolid, La Razón- posteriormente publicaciones on-line -Centro Virtual Cervantes-y los grupos de comunicación-Promecal-. 
Ambas facetas, agudeza de pensamiento y brillantez de escritura, fueron desarrollándose fuera de la prensa en una carrera literaria extensa y variada -novelas, narraciones breves, ensayos, diarios, poemarios- que ha obtenido reconocimientos públicos: en 1988 el Premio Nacional de la Crítica de Novela en Castellano y el Premio Castilla y León de las Letras; en 1992 el Premio Nacional de las Letras Españolas, el Premio Luca de Tena de Periodismo, el Premio Provincia de Valladolid a la Trayectoria Literaria en 1996, la Medalla de Oro al Mérito en las Bellas Artes en 1999 y el V Premio Nacional de Periodismo Miguel Delibes de 2000. Como digno colofón de todos ellos, el 12 de diciembre de 2002 se le concedió el Premio de Literatura en Lengua Castellana Miguel de Cervantes.

La personalidad de Jiménez Lozano no deja de sorprender. Nació en un pueblo, se trasladó con su familia a otro y en él se quedó. No necesita habitar en el mundo urbano para ser un referente importante de la cultura de España. Alcazarén no es el lugar rústico que el hombre de ciudad elegiría como destino de turismo rural. No se adecua a sus características: sus parajes no son especialmente bellos, ni propician la práctica de algún tipo de ocio o deporte en boga. Tampoco posee más bellezas artísticas que los elementos mudéjares de su iglesia parroquial. Desde el punto de vista intelectual tampoco es foco de cultura o que se promueva como tal, como sucede en otros pueblos de la provincia, como es el caso de Urueña ${ }^{1}$. El hecho de residir en ese pequeño lugar responde a la coherencia con su modo de estar instalado en el mundo. Algo que sorprendía al amante y defensor de la vida en el campo, Miguel Delibes, quien le proponía en la década de los sesenta instalarse en la ciudad: "Pepe Lozano vive retirado en un pueblecito de Valladolid, Alcazarén, con sus casas de adobe, su barro, su trigo y su pobreza. También algún pino que otro para disfrazar la aridez. Allí estudia, escribe, allí trabaja: - Oye, Pepe, ¿por qué no te vienes aquí a Valladolid? - Por ahora, no interesa." (Delibes, 1968, pp. 118-119).

El encuentro con José Velicia tuvo un marco singular: una librería en el medio rural: "Así que de un encuentro en una librería, y de muchas charletas allí con el librero, y luego tomando un café nació nuestra amistad, y ésta se nutrió enseguida de otras charlas en su apartamento junto a la Iglesia de San Pedro, y ni que decir tiene que se solidificó muy pronto." (Jiménez Lozano, conferencia inédita pronunciada en 2007). La amistad entre ambos se fraguó lentamente, con el tranquilo discurrir de lo doméstico, que deja huella indeleble en las almas: "La tienda de libros, bien diferenciada de la papelería y la venta de libros escolares (...) allí había un abate, que era José Velicia, un aspirante a servir al Estado u opositor, que era yo mismo, y el librero que, como José y yo averiguaríamos más tarde, había sido masón, y había llegado al pueblo -Olmedo, en Valladolid- en calidad no sabíamos si de desterrado o, con su sambenito encima, para buscarse la vida en un rincón pequeño." (Martínez Duque, 2002, p. 125)

No resultan baladíes las notas sobre aquella librería: un lugar de cultura, erguido en medio de un pueblo castellano, alrededor de un hombre de excepcional relación con los libros: "Y que con el tiempo nos enteramos por él mismo que era alguien, desde luego con un nivel cultural de cierta altura, testigo de un tiempo y una historia más que interesantes, y de una pasta humana nada común, y digamos también que alguien nada políticamente correcto según la ortodoxia de entonces, y que había pagado por ello, y cuya esposa, una mujer muy devota, llevaba un apellido ilustre y bastante triste en la lucha anticlerical más feroz. Y lo que hoy resulta casi incomprensible, en aquella papelería, cuyos libros en su mayoría eran escolares, como era lógico, podían verse y adquirirse libros, en especial novelas que eran pura y simplemente la gran novela sobre todo extranjera de la época, desde Faulkner a Bernanos, y, desde luego Stephen Zweig o Franz Werfell que ahora descubren quienes leen todavía. Y obviamente no tenía muchos clientes tal literatura, pero el librero sabía que su establecimiento no podía llamarse librería sin tener libros, y un librero podía entonces tenerlos porque la distribución no era un gran negocio todavía, y confiaba, de todos modos, en que alguien se llevara un libro en vez de un best-seller. Y se daba el caso, ciertamente" (Jiménez Lozano, conferencia inédita pronunciada en 2007).

La riqueza de aquella relación desbordó el ámbito de sus personas, dio lugar a infinitos mundos, a una pléyade de amigos, algunos en el presente y muchos durmiendo en el recuerdo de la historia. Apoyándose en los libros, traspasaban las fronteras de lo circunstancial, del tiempo y del espacio en el que estaban incardinados. Ello fue creando el humus en el que fecundó, de manera natural, el proyecto en cuestión: "José Velicia era, en el pueblo, coadjutor de una de las parroquias y profesor en un colegio; y buena parte de esos inicios de nuestra amistad se pasaron, además de en la charla y en el intercambio de libros, en asistir por mi parte a sus preparaciones instrumentales para que los chicos oyeran música y miraran láminas de arte, porque eso era hermoso y todo el mundo debía 
verlo. Y yo creo que Las Edades del Hombre comenzaron entonces" (Martínez Duque, 2002, p. 125).

\section{LA GÉNESIS DE UNA AVENTURA CULTURAL}

Las palabras pronunciadas por José Jiménez Lozano en la conferencia reiteradamente citada nos servirán para narrar la idiosincrasia del proyecto: "Y esto me dará pie para decir dos palabras sobre el asunto de Las Edades del Hombre. Esta serie de exposiciones se debe pura y exclusivamente a la idea que se le cayó a José Velicia de las manos mientras estábamos asando patatas en la chimenea de la cocina en que trabajo con frecuencia. José Velicia acababa de llegar de Barcelona donde había visto una exposición realmente de joyas artísticas, pero como amontonadas con un excelente pero frío criterio académico. ¿Qué podríamos hacer en esta tierra nuestra para mostrar el patrimonio artístico de ella? Y nos pareció que podría hacerse de otro modo más vital, según la sucesión del sentimiento religioso" (Jiménez Lozano, conferencia inédita pronunciada en 2007).

Tres ideas se desgajan de este fragmento: la primera relacionada con su creador -visita de Velicia a una exposición en Barcelona-, la segunda con el entorno en el que nació -la amistad-y la tercera con sus primigenias características -“modo más vital, según la sucesión del sentimiento religioso"-.

En la rotundidad con que Jiménez Lozano afirma que su origen se debe exclusivamente a José Velicia se vislumbra que ciertas sombras se ciernen sobre la autoría de un proyecto que llevaba, en el momento de pronunciar aquella conferencia, dieciocho años de recorrido. Quizás no la negación de la misma, pero sí su oscurecimiento, algo que se difumina ya desde el inicio, en el documento elaborado para presentar el proyecto a las autoridades y posteriormente en los catálogos de las exposiciones. Su nombre aparece como el telonero que deja paso a las palabras de los obispos de Castilla y León, quienes presentan una iniciativa que secunda las orientaciones del Concilio Vaticano II sobre la relación de la fe con el mundo contemporáneo, así como la llamada de Juan Pablo II a reenvangelizar Europa por medio de la cultura. Ciertamente sin la aquiescencia de los obispos no se hubiera podido llevar a cabo un proyecto que contaba como material con el patrimonio artístico de la Iglesia. También es cierto que la idea encajaba con el deseo de la Iglesia de acercarse al mundo contemporáneo. Pero Las Edades del Hombre no nacieron para responder a ellos, ni como fruto de una reflexión conjunta de los titulares de las diócesis, ni de ninguna iniciativa pastoral. Se tejió en las conversaciones de los dos Josés. Es más, a pesar de las repetidas afirmaciones de Jiménez Lozano de que fue solo una idea de Velicia, sostenemos que fue fruto de ambos, dado el importante papel que tuvo el escritor. La iluminación de Velicia encontró el eco adecuado en él, se nutrió del mismo afán de cultura, del mismo amor a las tierras castellanas, a sus obras, a su gente, a su pasado.

La segunda idea que se desprende del texto es el entorno en el que nació: "mientras estábamos asando patatas en la chimenea de la cocina en que trabajo con frecuencia". Esta extraña y poco académica manera de explicarse puede parecer en una primera impresión un exabrupto. Sin embargo enmarca el espacio geográfico de la amistad: el doméstico, el cotidiano, hecho de patata y trabajo, una expresión plástica de autenticidad. Queda subrayado por las palabras con las que inició su intervención: “Lo primero que quiero decir ante ustedes es que yo no estoy aquí para dar una conferencia, sino para ofrecer un testimonio de amistad" (Jiménez Lozano, conferencia inédita pronunciada en 2007). En la Ética a Nicómaco Aristóteles la define como "lo más necesario para la vida", por lo que "nadie querría vivir sin amigos, aun estando en posesión de todos los otros bienes", y a los amigos como "dos cuerpos con una sola alma". Las Edades del Hombre alargan sus raíces hacia el momento en que aquellos hombres se conocieron y se reconocieron como almas que podían caminar juntas "años y leguas", parafraseando el título que Jiménez Lozano dio a aquella conferencia: "Creo que no le hubiera disgustado nada a don José Velicia este título de 'Años y leguas con José Velicia' que he puesto a esta mi recordación pública, y que es el título de una de las novelas de Gabriel Miró, como resumen de nuestro encuentro y nuestra amistad. Porque realmente han sido años de una amistad muy profunda y en los que hemos recorrido no solamente la materialidad de muchos kilómetros, sino también leguas y navegaciones en otros mundos, los de la interioridad y la cultura" (Jiménez Lozano, conferencia inédita pronunciada en 2007). La elección de este libro de Gabriel Miró arroja luces. En él ofrece una serie de reflexiones de cariz filosófico a raíz de las observaciones del paisaje de su tierra. Plasma sus vivencias personales: un espacio, una tierra, humanizada por la mirada de un pensador (Laín Corona, 2010). Se acomoda bien a lo que Velicia y Jiménez Lozano compartían: contemplaban la realidad con el prisma de la pasión por la belleza, por el arte.

La lógica de la amistad fue el marco de Las Edades -altruismo, lealtad, compartir ilusiones, confiarse 
pensamientos- y de su lenguaje: el amistoso, de recreo, con la simple ambición de alargar aquellas conversaciones sobre el pasado, el presente y las obras artísticas a través de una puesta en escena a la que invitaban a quienes fueran capaces de seguir el entramado de su amistad: "Tales fueron los orígenes, pero afortunadamente en este caso sí pudo ver Velicia la andadura de medio sueño, medio invento, que se hizo medio jugando, pero cuyo trasfondo estaba en el no infrecuente comentario de tantas visitas y estancias viendo pinturas y otras hermosuras: "Esto habría que sacarlo a relucir a la calle para mostrarlo" (Jiménez Lozano, conferencia inédita pronunciada en 2007).

"Medio sueño, medio invento" es como Jiménez Lozano define a Las Edades del Hombre. Un modo de decir casi idéntico al que emplea José Velicia del que testimonia unas palabras suyas en la dedicatoria que escribió a Michael Reckling, a quien le agradece "por la acogida fervorosa, por la expresión plástica de nuestra utopía y nuestro sueño".

Figura 1. Dedicatoria de José Velicia a Michael Reckling, 1980. http://www.catedral-valladolid.com/ in-memoriam/jose-velicia/index.htm, consultado el 29 de abril de 2014

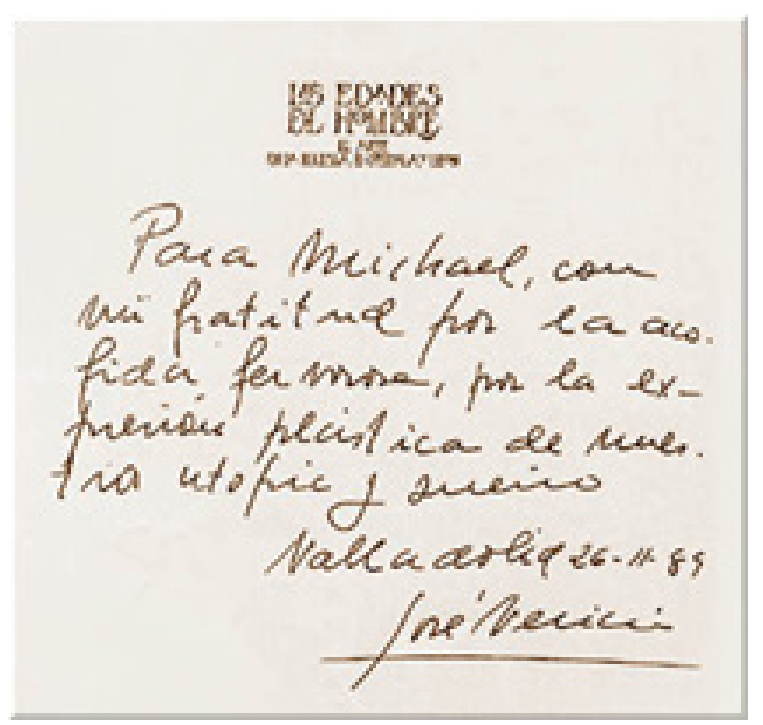

La tercera idea que se desprende del texto que estamos analizando hace referencia a una de las señas de identidad más importantes sobre el modo de concebir la exposición de arte, "de otro modo más vital, según la sucesión del sentimiento religioso" (Jiménez Lozano, conferencia inédita pronunciada en 2007).
Una vez enmarcada la génesis del proyecto exposivito, nos centramos en la aportación de José Jiménez Lozano a ella.

\section{LA APORTACIÓN DE JOSÉ JIMÉNEZ LOZANO}

Eloísa de Battenberg, Amando Represa, Juan José Martín González, Sebastián Battaner, Pablo Puente Aparicio, M. a Antonia Virgili, etc. son algunos de los numerosos testigos de la aportación de José Jiménez Lozano a Las Edades del Hombre. Todos ellos fueron puntales en la puesta en marcha del proyecto, ganados por el entusiasmo y capacidad de hacerse amigos de José Velicia. En un libro publicado en homenaje al sacerdote ya fallecido, así lo atestigua Amando Represa: “En unión con nuestro común amigo, José Jiménez Lozano, empezaron a fraguarse Las Edades del Hombre en las ya lejanas tardes del invierno de 1985, al amor de un braserillo en Alcazarén, en el que los dos Pepes platicaban, discutían y programaban el acontecimiento" (Martínez Duque, 2002, p. 125). Sin embargo, el mayor garante es el propio Velicia, quien escribe: "La prosa debida a José Jiménez Lozano, una de las plumas más lúcidas y vigorosas del mundo de las letras, y cuyo nombre está inseparablemente unido a esta apasionada aventura cultural." (Jiménez Lozano, 1990).

Su contribución reviste múltiples facetas que van desde la fundamental, su amistad y apoyo a Velicia y la contribución de su bagaje cultural, a los múltiples consejos, la ayuda en la elección de obras artísticas, la redacción de escritos y publicaciones, su influencia en terceras personas en el modo de colaborar con el proyecto, etc. Esta última se detecta en algunas iniciativas, como es la de Adolfo Calleja de tomar un fragmento de las pinturas de San Baudelio de Berlanga ${ }^{2}$ para diseñar el logosímbolo de Las Edades, o la idea de Pablo Puente de incluir un óculo cisterciense en un capítulo de la exposición. Otra influencia es la elección de Santa María de Valbuena como sede de la Fundación Las Edades del Hombre. Se trata de un monasterio cisterciense situado en San Bernardo, una localidad distante unos 45 kilómetros de Valladolid, fundado en el siglo XII para ayudar a la repoblación de la meseta. Su devenir cultural de siglos se frustró con las exclaustraciones y desamortizaciones del XIX, hasta que en 1964 el arzobispado de Valladolid recuperó su posesión. Existen artículos en la prensa publicados en 1977 en los que Jiménez Lozano habla de Valbuena y muestra su fascinación por aquellas ruinas en las que él veía huellas de un pasado preñado de espiritualidad, libros, belleza, modos de vida dedicados al estudio, distintas manifestaciones de cultura, etc. No es arriesgado aventurar que contagia- 
ra esta predilección a su amigo, José Velicia, y juntos albergaran el deseo de rescatarlo del olvido. Ante sus muros cerrados se pregunta si aquel pretérito hogar de cultura no podría volver a ser un foco de irradiación cultural y espiritual de Castilla. Eran los años de la transición democrática y las regiones españolas se encontraban en búsqueda de su propia identidad, por lo que, poco amigo de la política, apunta a la cultura como al registro desde el que debían construirse las sociedades, por lo que añade con ironía “(...) que seguramente lo necesita más que saber cómo es su propia bandera o pendón" (Jiménez Lozano, 12 de marzo 1977). Durante esos años se suceden las visitas a Valbuena, de las que saca reflexiones y deja constancia en sus artículos periodísticos (Jiménez Lozano, 19 de septiembre 1977).

Contribución suya, quizás no conocida, es el nombre elegido, Las Edades del Hombre, una denominación sugerente, abierta, indefinida, que produce extrañeza y al mismo tiempo abre la curiosidad y que recogió José Velicia de un poema del escritor que este destruyó posteriormente, según el autor nos confesó recientemente en una entrevista que tuvo lugar en Alcazarén el 13 de mayo de 2014.

Obviamos su aportación escribiendo los primeros guiones para los vídeos que se expusieron y varias publicaciones -El ojo del icono, Estampas y Memorias, el texto de la Cantata Las Edades del Hombre-por la carencia de espacio en este artículo y dado que salieron a la luz después de la primera exposición.

\section{HUMUS INTELECTUAL DE LAS EDADES DEL HOMBRE}

La aportación más peculiar de José Jiménez Lozano reside en su bagaje intelectual que marca la hondura del proyecto. La lectura de su obra periodística entre los años 1970-1980 y de su libro Guía espiritual de Castilla, arroja interesantes luces que dan visibilidad al humus en el que germinó la iniciativa de Velicia, de quién solo podemos documentar su alto nivel cultural por los testimonios que de él se han dado y, sobre todo, por el coloso que puso en marcha: Las Edades del Hombre.

Las publicaciones a las que nos referimos son anteriores a ellas. En la prensa se detectan las primeras señales en 1979, cuando faltaban diez años para que se inaugurara la primera exposición y algunos para que José Velicia visitara Thesaurus, la muestra de patrimonio artístico que fue su detonante. En una de ellas comenta el nacimiento de Capela, una revista dedicada a temas culturales promovida por personajes como Caro Baroja, Ramón Carande, Bernardo Víctor de Carande, Justino de Azcárate, Pedro Saínz Rodrí- guez, Buero Vallejo y Antonio Llopis. Se alegraba de su existencia y explicaba así la razón de ser de aquella publicación: “(...) quiere servir de lugar de encuentro cultural o espiritual para quienes tienen una determinada concepción del hombre y pretenden continuar con el pensamiento de aquellos que la tuvieron en el pasado" (Jiménez Lozano, 26 de mayo 1979). Dos notas importantes se desprenden de este párrafo: la importancia que concedía a la cultura, a la historia y la consideración del hombre como núcleo de las propuestas culturales. Y sobre todo, llama la atención cuando califica la iniciativa de aquellos hombres como “(...) la labor de los monjes medievales de rescatar la cultura de la barbarie. Nuevos monjes que nos enseñarán el trabajo de miniar el trabajo y la paciencia, la delicadeza y los escrúpulos de las tareas intelectuales" (Jiménez Lozano, 26 de mayo 1979).

La mención a los monjes sigue la estela de las reflexiones en torno a las visitas al monasterio de Valbuena. Se hace explícita en un artículo publicado en El País. Con ocasión de los quince siglos del nacimiento de Benito de Nursia, hace suyas las palabras de Aldous Huxley cuando declaraba que el benedictinismo "civilizó el noroeste de Europa, implantó o restableció los mejores métodos agrícolas de su tiempo, proporcionó los únicos elementos de educación entonces disponibles y conservó y diseminó los tesoros de la literatura antigua. Durante generaciones, el benedictinismo fue el principal antídoto contra la barbarie" (citado en Jiménez Lozano, 2 de abril 1980). Se va afirmando, en Jiménez Lozano, el sueño de rescatar la cultura para proponerla como medicina a la sociedad actual y su convicción de que esa labor vendría de la mano de unas cuantas personas capaces de retomar el espíritu de trabajo, seriedad y amor por la belleza de aquellos cistercienses.

Un mes más tarde escribe, en el mismo periódico, sobre el lamentable estado del patrimonio artístico en España y ahonda sobre su importancia: "Cuando todo haya acabado de caer -si es que esta hora no está llegando o no ha llegado ya- se comenzará a parlotear de cultura o de historia y arte, que, para más «inri», en nuestra sociedad tecnológica también se han convertido en saberes esotéricos y técnicos con sus expertos. Como si la belleza no estuviera ahí para ayudar a vivir y a transcenderse a todos los hombres, como si el arte y la conciencia de identidad histórica no fuera necesario que estén ahí, para permitirnos seguir siendo hombres, y no meros supervivientes biológicos cercados de coches, de snaks o pubs, de silos y garajes, más interesantes ya para tantos seres humanos que la Moreruela o San Clemente de Tahull”, (Jiménez Lozano, 17 de mayo 1980). 
Queda patente su concepción de las obras de arte heredadas del pasado, que iluminan el vacío del mundo consumista y tecnológico al que parece estar abocada la contemporaneidad, pues empezó destruyendo patrimonio: la Revolución Francesa, la soviética, las desamortizaciones españolas, las destrucciones de la Guerra Civil. A esos desmanes compara la incultura contemporánea, manifestada en deshacerse de antigüedades o en la frivolidad de comprarlas, simplemente, como una mera inversión. Lo que está siempre en riesgo es la belleza y, con ella, algo de capital importancia para el hombre, como explica al recordar cuando Gorki intentó convencer a Lenin para que no demoliera las iglesias, pues implicaba arrancar los iconos de ellas: "Gorki le escribió una carta en la que le disculpaba de tan brutal idea sólo en razón de su condición de aristócrata que no podía comprender lo que la belleza de los iconos significaba para las gentes pobres que ni siquiera habían comido, para quienes la vida era terrible: las iglesias deberían permanecer ahí con sus pinturas y sus oros; el único tesoro del pueblo. Pero hablaba en balde. Y el fanatismo y la idiocia de los burócratas del partido se encargarían, al fin, de arrasar todo o de concentrar aquellos tesoros en museos especiales como testimonio de una época de superstición sin planes quinquenales (...)" (Jiménez Lozano, 17 de mayo 1980). Estas palabras, escritas en 1980, resultan de gran trascendencia, pues expresan con claridad una de las características clave de Las Edades: exponer las obras de arte en el contexto para el que fueron creadas, esto es, los recintos sagrados. El hecho de que se eligieran posteriormente las catedrales, fue solamente una concreción de ello. Por otro lado, refleja la fascinación de Jiménez Lozano por el término y el significado del "icono", con el titula la primera publicación que aparece bajo el sello de Las Edades del Hombre en 1988, El ojo del icono, un ensayo sobre el arte.

En su obra Guía espiritual de Castilla tenemos acceso a su particular acercamiento al patrimonio artístico de Castilla y a las reflexiones que le suscita. Publicada en 1984, es una obra de difícil catalogación a la que se le concede el título de ensayo (Ibáñez Ibáñez, 2005), pero no es esta la intención del autor que modestamente señala en su prólogo que pretende ofrecer "algunas claves y meditaciones para acercarse a las expresiones o a la vida misma de nuestro pasado. (...) subrayar de qué modo y manera los universales sueños y esperanzas del hombre y la propia realidad de la vida cotidiana se encarnaron aquí, entre nosotros, de una forma que resulta significativa en el plano humano, espiritual o artístico para todo el mundo" (Jiménez Lozano, 1984, p.
11). La palabra 'sueño' concuerda con el modo como él mismo define años más tarde a Las Edades del Hombre, como ya se ha señalado. Las palabras finales del libro manifiestan su propio juicio en torno al estudio que propone: "Tampoco sabemos muy bien, al fin y al cabo, qué es Castilla, después de todo ese buceo en ella. Siempre queda un poco más allá, siempre asoma un poco más profundamente" (Jiménez Lozano, 1984, p. 294). Es decir, a través de las manifestaciones artísticas, intenta comprender y desvelar el pasado de una tierra y unas gentes, sin pretender hacer un catálogo de ellas, ni centrarse en un estudio académico. A lo largo de veinticuatro capítulos se acerca a monumentos y hechos culturales de la región, algunos pocos conocidos, los enmarca en el tiempo en el que nacieron y los acompaña de reflexiones propias o de pensamientos de otros autores. Inicia el recorrido en un lugar recóndito y bastante desconocido: la ermita de San Baudelio de Berlanga, en Soria. A lo desconcertante de esta elección se añaden unas palabras que indican que nos encontramos ante un pensador original, cuando declara como imprescindible comprender la impronta árabe en estas tierra: "Y, por fuera y por dentro, la historia y el alma colectivas, los sentires, pensares y vivires de Castilla son ciertamente fronterizos, y para adentrarnos en ellos hay que pasar por un arco de herradura." (Jiménez Lozano, 1984, p. 15). Su defensa es tal, que no extraña que Adolfo Calleja incorporase un fragmento de las pinturas de San Baudelio, en el logosímbolo de Las Edades.

El análisis de esta obra a la luz de las exposiciones de Las Edades del Hombre podría llevar lejos, pero nos interesa detenernos en un par de comentarios en relación con el arte y en su referencia a Santa María de Valbuena. El primer comentario viene a propósito de ciertas temáticas burlonas que el románico luce en capiteles, sillerías y canecillos. En ellos “(...) son denunciados todos estos vicios humanos con la punzada crítica y llena de sarcasmo con que sólo el arte puede hacerlos, y como sólo el arte puede ayudar al hombre a aspirar a serlo por encima mismo de la mediocre realidad cotidiana de su vida." (Jiménez Lozano, 1984, p. 127). En ella encontramos una declaración explícita sobre la consideración del arte como un instrumento fundamental para la maduración de las personas en tanto que ayuda para superar todas las deficiencias de la existencia propia y ajena.

Otro interesante comentario lo realiza al explicar que la prosperidad mató el espíritu cisterciense pues le llevó, entre otras cosas, a que sus edificaciones fueran como "construcciones que eran copia de sí mismas, se enfatizaron y agigantaron, y se caricaturizaron 
y vaciaron al final. Ya no estaba en ellas la búsqueda de la pura forma, que es esencia del ser; ni la belleza se definía ya por lo que no estaba allí. Así que siempre hay que buscar lo más humilde y sencillo y no dejarse fascinar por los nombres ni las grandezas de la historia. Ni pasar deprisa o permanecer satisfechos con los datos técnicos y el conocimiento material de estas construcciones. Como si cuando se conoce el nombre de una cosa -decía también san Bernardo de Claraval- se conociera la cosas misma" (Jiménez Lozano, 1984, p. 114). Estas interesantes notas sobre las propiedades del arte, algo puro, auténtico y significativo en sí mismo, tendrán una importante plasmación en las exposiciones. Un ejemplo es la exaltación de lo humilde y sencillo, en la recreación que se hizo en Valladolid de la estancia de un monasterio de carmelitas.

De nuevo aparece Santa María de Valbuena, "(...) esos arcos claustrales de elegantísimo y femenino calado o, casi ciegos, con sus 'oculus' como místico Polifemo que apunta en su mirada a una belleza, que no está ante nuestros ojos pero que se presentiza", (Jiménez Lozano, 1984, p. 111). Se trata de una nueva nota sobre la belleza, esa capacidad para hacer visible lo invisible y dotar de trascendencia a lo que parece que no la tiene. El impacto de estos comentarios tuvo su encarnación plástica en la primera exposición de Las Edades del Hombre. Pablo Puente Aparicio, que no conocía a Jiménez Lozano pero sí este escrito, aprovechó un pequeño espacio vacío del recorrido arquitectónico para diseñar un arco del monasterio cisterciense: "Planteé hacer una réplica (...) Hasta que un día pasó por allí Pepe Jiménez Lozano. Estábamos Eloísa y yo trabajando y rematando cosas, cuando apareció Velicia anunciándonos que había llegado Pepe (Jiménez Lozano) a verlo. (...). Lo que yo conocía de Pepe eran unos escritos muy bonitos, pero después había que hacer con eso una exposición. Salió encantado. Velicia lo repetía con emoción, ile ha gustado mucho!". Así lo indicó en la entrevista que tuvo lugar en Valladolid el 22 de junio de 2010.

Con estas consideraciones se pone de manifiesto la catadura intelectual de Jiménez Lozano, atesorada durante años y reflejada en sus escritos, en la que secundó añadió la ambiciosa propuesta expositiva de su amigo Velicia.

\section{EXPLICANDO UN SUEÑO}

Una importante plasmación de la aportación de José Jiménez Lozano a Las Edades del Hombre es su intervención en la Presentación de la exposición, un texto anónimo y sin fechar. Había que explicar el "medio sueño, medio invento" a las autoridades eclesiásticas en tanto que responsables del patrimonio artístico de la Iglesia, y a las civiles para pedir ayuda y autorización. Para ello se elaboró un texto del que existen varias versiones. Hemos tenido acceso a tres ejemplares, los tres diferentes: uno pertenece al archivo de la Fundación Las Edades del Hombre, otro a José Jiménez Lozano y otro a Pablo Puente Aparicio. No es difícil deducir cuál es el originario a través de una serie de notas externas -la tipografía y el símbolo-e internas -el texto-. El de Puente posee unas características diferentes del resto ya en la portada: ausencia de la tipografía y el símbolo propio de Las Edades, así como el texto "Proyecto financiado por la Caja de Ahorros y Monte de Piedad de Salamanca para una Exposición". Este último se cambia en los otros ejemplares en "Proyectan: las diócesis castellano-leonesas y patrocina la Caja de Ahorros de Salamanca y la Junta de Castilla y León. La foto de la Sedes Sapientae coincide con el fragmento publicado en Los ojos del icono, lo que sigue indicando que la mano de Jiménez Lozano aletea por allí.

Figura 2. Ejemplar del archivo personal de Pablo Puente Aparicio

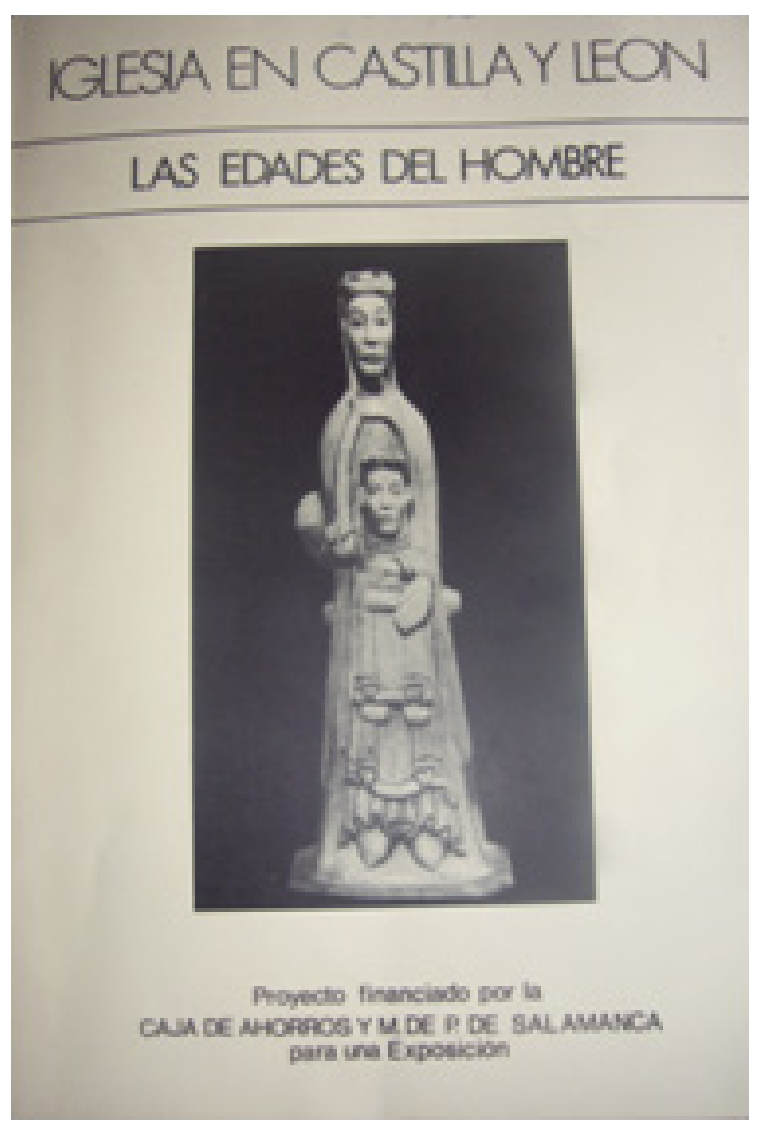


Figura 3. Ejemplar del archivo de la Fundación Las Edades del Hombre

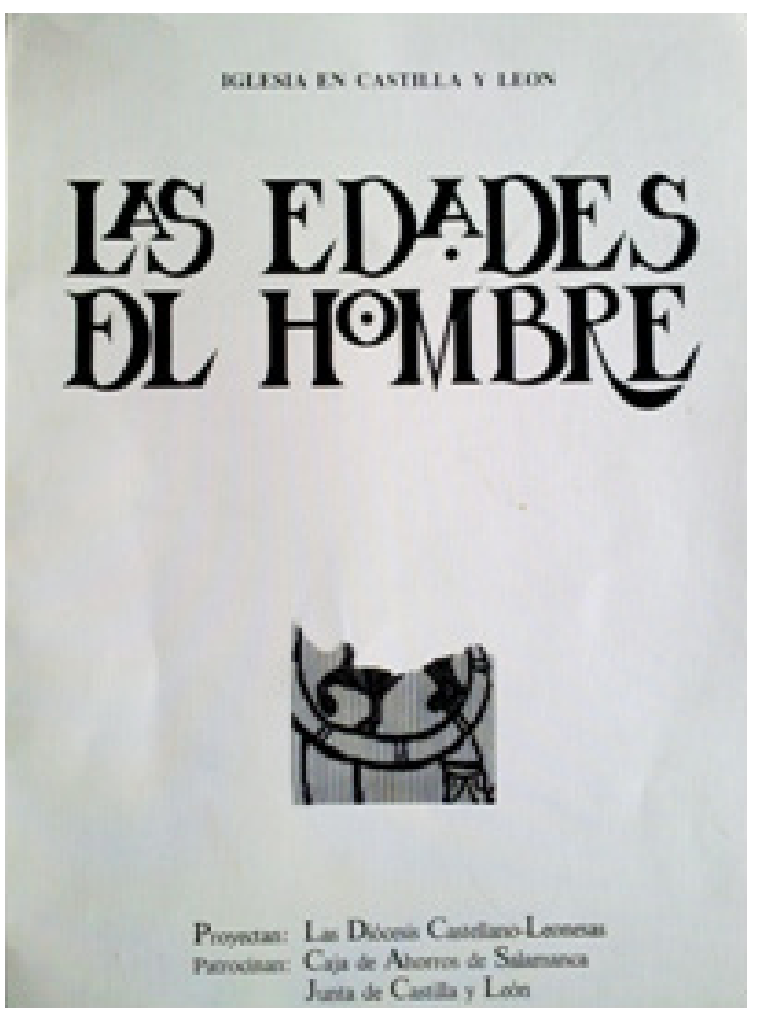

En relación con el contenido, el de Puente se abre con unas palabras del titular de la diócesis de Valladolid, José Delicado Baeza que, en los otros ejemplares, rubrican el resto de los obispos de Castilla y León, lo que hace pensar que ha transcurrido un tiempo en el que se ha ido dando a conocer la iniciativa a los once mitrados, quienes la avalan y presentan como una iniciativa de la Iglesia.

El librillo se estructura en cuatro capítulos entre los que destaca el segundo, "Teoría general y esquema de la exposición", en el que se explica la esencia de la muestra. Aunque no está firmado se reconoce en él la mano de Jiménez Lozano. Su factura es muy distinta a la del primer capítulo, en el que se hacen referencias teológicas y citas del magisterio de la Iglesia. El autor recurre a personalidades del mundo del arte -pintores, musicólogos, escritores, estudiosos-, todos contemporáneos y ninguno ligado a la Iglesia, algo que es característico de la escritura del abulense (Merino Bobillo, 2011). Comienza reflexionando sobre el objeto material de las exposiciones, sobre el que da un toque de atención: "En términos jurídico-administrativos que han sido acuñados en época burguesa, ese conjunto artístico lleva el nombre de patrimonio, que desnaturaliza del todo su carácter primario y esencial: se habla en efecto de "tesoros" más que nada por su valor de prestigio social y cultural y su cotización económica desatan la codicia del Estado, de instituciones de toda clase y de los ciudadanos", (Las Edades del Hombre. Presentación, p. 7).

Lo importante, señala, no es el valor de las piezas, sino lo que significan para el hombre, en tanto que este es un ser capaz de belleza, buscador de la trascendencia y necesitado de expresar ambas: “(...) ese cúmulo de bellezas es, por lo pronto y de manera esencial, la memoria del pasado: una memoria histórica de los hombres y de su vividura de lo Invisible, de la fe cristiana de una colectividad concreta que así se ha explicitado plásticamente a través de unos relámpagos de belleza. Y, sin duda, en un mundo como el nuestro, es preciso señalar esa memoria y su condición no arqueológica, sino existencial y por lo tanto contemporánea." (Las Edades del Hombre. Presentación, p. 7). El término "vividura" es sello inconfundible de la escritura lozaniana (Merino Bobillo, 2011). El pasado ilumina la andadura del presente, una afirmación que constituye el núcleo de la filosofía de Las Edades del Hombre.

Sobre las piezas que se expondrán, aclara que muchas serán conocidas, puesto que lo que se propone no es la novedad, sino reunirlas contando un relato dentro del marco para el que han sido creadas, el entorno religioso, pues cuando se exhiben fuera se les resta parte de su sentido: "E incluso hay que decir que ningunas condiciones mejores que las de acercarse a ellas "in situ" para comprender su profunda razón de ser, tanto desde el punto de vista histórico en general como el de la historia específica del sentimiento religioso; y en muy amplia medida, un museo o una exposición tienen siempre algo o mucho de almacén o exhibición y no sólo escamotea a cada obra artística su especial relucencia y esa ligazón esencial con el medio en que ha sido producida, sino que la ofrecen poco más que admiraciones superficiales y glosa más o menos eruditas." (Las Edades del Hombre. Presentación, p. 7).

Ello invalidaría la razón de la exposición que se propone, por lo que sale al paso de esta objeción: "De manera que un museo o una exposición sólo tienen vida y profundo sentido, cuando son entendidos y configurados como "mostra" de un artista, de un movimiento artístico o "a fortiori" de un espíritu que ofrece toda la polisemia de sus contenidos a través del tiempo y de las distintas formas en que se nos revela. 
Y éste es el caso, y de manera absolutamente singular, además." (Las Edades del Hombre. Presentación, p.7).

Todavía una aclaración previa al meollo del texto es la afirmación de que no se trata de una exposición de arte religioso. Tal sentencia puede parecer una provocación si no se lee la explicación: "Lejos la idea de una exposición de arte religioso. Esta sería una pretensión absolutamente falsa y falseadora de lo que es el arte y de lo que es el ámbito de lo religioso, una idea derivada solamente de la trágica ruptura entre religión y arte, que se consuma en el último barroco y determina una situación a la deriva de ambas realidades." (Las Edades del Hombre. Presentación, p. 8). El autor hila fino y demuestra un conocimiento profundo y nada convencional sobre el arte y su devenir en la historia.

A partir de aquí, se adentra en la teoría y lo hace de la mano de tres expertos. El primero de ellos es Henri Posseur, musicólogo belga en plena actividad profesional durante los años en los que se gestaban Las Edades del Hombre. Toma sus palabras para argumentar su anterior juicio sobre el arte religioso: "Si hasta entonces -dice Henri Posseur- no había, por ejemplo, ninguna diferencia entre arte sacro y profano, si ambos se nutrían de manera recíproca y continua, si había óleos que sin gran dificultad podían pasar de un campo a otro, a partir del siglo XVIII se desarrollará un arte que será llamado "religioso", pero que con mayor exactitud habría que llamar simplemente eclesiástico e incluso clerical, y que, alejado de la vida corriente, de sus valores concretos, se atenuaba con una gran rapidez mientras que el arte laico o popular ve secadas sus mismas fuentes y se irá extinguiendo hasta ser sustituido del todo por la pura comercialidad." (Las Edades del Hombre. Presentación, p. 8).

Con otro autor contemporáneo da un paso más en la argumentación y parece negar lo que acaba de sentenciar como correcto. Se trata de Paul Klee, un pintor que viajó desde el surrealismo, al expresionismo y posteriormente a la abstracción: "Todo arte es, por su naturaleza misma, revelación de lo Invisible, que decía Paul Klee; todo arte es irremisiblemente religioso, porque trata de tocar la ultimidad y de mostrarla en la belleza o en lo horrible, trata de la realidad que no es la historia, pero es más fuerte que ella." (Las Edades del Hombre. Presentación, p. 8). La problemática del término religioso proviene si se le identifica con alguna derivación -eclesiástico, litúrgico-y se reduce a ella su amplio significado, quizás mejor expresado en el término 'espiritual'.
En tercer lugar, cita a una de las máximas autoridades mundiales en arte oriental del momento, Ananda Coomaraswamy. De él toma el propósito que debe tener un museo o una exposición: "Ananda Coomaraswamy, tantos años al frente del Museo de Boston, ha escrito precisamente a propósito de lo que debe de ser un museo o una "mostra". "La función de un museo o de cualquier educador no consiste en halagar o divertir al público. Si la exhibición de obras de arte, como la lectura de los libros, ha de tener un valor cultural, es decir, si ha de alimentar y cultivar lo mejor que hay en nosotros, como las plantas se alimentan y crecen en un terreno adecuado, lo que hay que estimular es la inteligencia y no los sentimientos refinados." (Las Edades del Hombre. Presentación, p. 8).

La densidad del proyecto Las Edades del Hombre comienza a perfilarse nítidamente. No se trata tan solo de provocar emociones artísticas, sino de enriquecer el interior de las personas, una consideración que se asemeja mucho a la que José Jiménez Lozano posee sobre el valor y la función del libro. ${ }^{3}$ Continúa explicitando los objetivos de la exposición a través de las palabras del experto en esoterismo tradicional hindú: "En un aspecto el público tiene razón; siempre quiere saber "de qué trata" una obra de arte. ¿En qué, como preguntaba Platón, nos hace el sofista tan elocuente? Digámosle de qué tratan estas obras de arte y no nos limitemos a decirles cosas sobre las obras mismas. Digámosle la penosa verdad: que la mayoría de estas obras hablan de Dios, a quien nunca mencionamos entre personas educadas." (Las Edades del Hombre. Presentación, p. 8). Coomaraswamy señala con decisión uno de los complejos sociales de Occidente que, tras siglos de huella cristiana, se avergüenza y parece renegar de su herencia. Sin embargo, las piezas artísticas religiosas remiten a ese Ser Primero y están preñadas de significado: "Admitamos que si hemos de dar una educación de acuerdo con la naturaleza profunda y la elocuencia de las obras expuestas, no será una educación de la sensibilidad, sino una educación filosófica en el sentido platónico y aristotélico de la palabra, esto es, como ontología y teología, como plan vital y como sabiduría destinada a ser aplicada en los asuntos cotidianos." (Las Edades del Hombre. Presentación, pp. 8 y 9).

De ahí que defienda una apreciación del arte que trascienda lo meramente estético y apunte a la interioridad del hombre: "Admitamos que no hemos conseguido nada, si lo que hemos de exponer no influye en la vida de los hombres y no cambia sus valores. Adoptando este punto de vista, eliminaremos la dis- 
tinción social y económica entre las bellas artes y reconoceremos que la aproximación antropológica al arte es un modo mucho más riguroso de enfocar el problema que el del esteta; abandonaremos la pretensión de que el contenido de las artes populares sea otro que un contenido metafísico. Enseñaremos a nuestro público a exigir lucidez por encima de todo en las obras de arte... Distingamos netamente entre la "educación visual" que sólo nos dice qué aspecto tienen las cosas (dejándonos "reaccionar" como debemos) y la iconografía de las cosas que en sí son invisibles (por las cuales podemos saber cómo actuar)." (Las Edades del Hombre. Presentación, p. 9).

La tercera referencia es Walter Andrae, el arqueólogo alemán especialista en el mundo mesopotámico. Con él sigue profundizando en el auténtico significado del arte: "Hacer inteligible la verdad primordial, representar el arquetipo, ésta es la tarea del arte o sino, no es arte." (Las Edades del Hombre. Presentación, p. 9). Aporta otra nota sobre él, su esencia universal.

La última voz de autoridad pertenece a Frithjof Schuon. Al igual que los anteriores autores, su amplia personalidad y su pensamiento son difíciles de resumir. Tiene en común con Coomaraswamy su procedencia oriental. Se trata de un místico que estudió y refundió algunas teorías hindúes. De Schuon toma su descripción sobre lo que es la contemplación de la obra de arte: “(..) esa experiencia profunda de la que ha hablado $F$. Schoun, cuando nos invita a reflexionar sobre la muy individualizada sensación o vividura que nos describe como experiencia artística de última instancia. "Ante una catedral -dice, aunque se diría más bien ante una iglesia románica y se negaría a la catedral, construcción funcional, ese lugar de parangón en la propuesta- uno se siente realmente situado en el centro del mundo; ante una iglesia de estilo renacimiento, barroco o rococó, uno no se siente más que en Europa». Exactamente como uno se siente en China o en un país árabe, si se encuentra ante un templo chino o una gran mezquita (...)." (Las Edades del Hombre. Presentación, p. 9).

El autor del texto defiende también la belleza de esos lugares, quizás más humildes y pequeños, pero que encierran en sí una carga de sentido que los convierte en sitios trascendentes y por tanto, universales: “(...) pero se siente también en el centro del mundo y en presencia de una poderosa e invisible belleza que nos sobrecoge, si nos situamos ante la humildísima tumba de ladrillo y cal pintados, de un morabito del Magreb o de un filósofo del Turquestán, ante una arquillo mudéjar o un oculus cisterciense." (Las Edades del Hombre. Presentación, p. 9).
Insiste en la presencia de esas bellezas en Castilla y en el deseo de mostrarlas de una manera particular, no como mera exhibición, sino como un viaje desde el pasado que ilumina al presente: "Y topoi o lugares de esa condición artística y espiritual umbilical hay en Castilla, e iconos. $Y$ esto es lo que se trataría de mostrar. Mostrando, al mismo tiempo, de qué modo esos iconos narran la aventura de la fe en esta tierra, el camino del hombre castellano en sus relaciones con lo Invisible, la memoria pasionis del hombre y de la belleza que le ha acompañado. Una belleza y sus contenidos, que sigue estando ahí y sigue hablándonos." (Las Edades del Hombre. Presentación, p. 9).

Finaliza el texto resumiendo lo que se pretenden exponer bajo el singular título de Las Edades del Hombre: "Se trataría, pues, de una memoria y de una experiencia para ahora mismo, porque la belleza no muere y lo que expresa es lo eterno e invisible o la historia de Cristo siempre contemporáneo. Y esto es lo que quiere decirse con este epígrafe general de esta mostra, Las Edades del Hombre y con la siguiente disposición mostrativa (...)". (Las Edades del Hombre. Presentación, p. 9).

En conclusión, todas las características del capítulo "Teoría general de la exposición" perteneciente a la Presentación de Las Edades del Hombre, remiten a la factura de Jiménez Lozano. Reflejan la exquisitez intelectual y la apertura mental del escritor. En solo tres páginas se apoya en cinco densas citas para ofrecer profundas e interesantes consideraciones, que marcan con claridad el espíritu que va a guiar el proyecto: presentar la memoria religiosa de un pueblo a través de unas obras de arte que se ofrecerán como itinerario de reflexión.

\section{EL GUIÓN DE LA EXPOSICIÓN}

En el tercer capítulo de la Presentación se anuncia el triple contenido de la exposición: iconográfica, bibliográfica y musical. Las dos últimas apenas quedan esbozadas, pero el simple comentario "la atención al erasmismo castellano puede privilegiarse" vuelve a indicar la factura de Jiménez Lozano, ya que se trata de un tema muy de su interés. (Las Edades del Hombre. Presentación, p. 14).

De nuevo su impronta se encuentra en la explicación de los diez capítulos en los que se estructurará la exposición iconográfica. Los títulos remiten a una mente literaria, así como su concepción a modo de relato que atraviesa la historia del hombre. "El sueño del Paraíso" le sitúa en sus orígenes, con la 
Creación y la llegada del mal en el mundo. "El Señor de la historia" presenta a Cristo como la clave por la que se entiende al hombre y su destino. "El ojo hacia lo invisible" salta en la historia hasta la estética cisterciense y, basándose en ella, alude a las relaciones de los hombres con la imagen religiosa a través de los tiempos, fluctuando entre la adoración y el miedo a la idolatría. En "El dolor y la sonrisa" se entrelaza la dureza de la peste del siglo XIV, la crisis de la cristiandad y la esperanza. La respuesta a esos terribles tiempos se muestra en "La crisis del XV: el Cristo muerto y sepultado". "Los trabajos y los días" supone un corte temporal para detenerse en la vida cotidiana de los hombres, la influencia de la organización litúrgica en sus vidas y los ejemplos recibidos a través de cristianos ejemplares. "El sueño de la muerte y la gloria" vuelve a recuperar la noción del tiempo histórico y se vuelca en el Renacimiento, con su énfasis en la belleza del cuerpo humano, reflejado también en la encarnación de Cristo y su expresión menos renacentista en Castilla. El barroco lo presenta en el capítulo octavo, con sus contrastes de luces y sombras: su pesimismo sobre el hombre y, al mismo tiempo, su gusto por la alegría en las cosas pequeñas y cotidianas. El noveno capítulo es un homenaje a una espiritualidad carmelitana, que tuvo su cuna en Castilla. "El silencio y la pobreza: el encanto y el espíritu de lo minúsculo" pone en relieve, frente a las obras de arte que se producen en ese momento en los Países Bajos, la belleza de la desnudez de sus objetos cotidianos, que todavía están presentes en sus conventos. El pantocrátor viene a decir, en el último capítulo, "El Señor de la muerte y de la vida", que la historia del hombre tiene un sentido y un final feliz.
Lo literario de los capítulos de la exposición, así como su significado, marcó un modo de presentar que se ha querido seguir desde entonces. La brevedad de este espacio no permite reproducir los textos completos de cada uno de ellos, ni los títulos de las posteriores ediciones, que pueden consultarse en los catálogos de las mismas.

\section{CONCLUSIÓN}

La impronta de José Jiménez Lozano en Las Edades del Hombre es de capital importancia. Sin ella, la catadura intelectual del proyecto habría revestido otras maneras. Su contribución es múltiple y la hemos estructurado en tres vertientes. La primera relacionada con el nacimiento y la esencia del mismo, la segunda con sus colaboraciones expresas y la tercera con la influencia que ejerce sobre terceras personas que, apoyándose en su auctoritas intelectual, se inspiran para sus creaciones. Lo más relevante de sus aportaciones, las que imprimieron carácter al ciclo de exposiciones, se encuentra latente en los escritos publicados antes de que Las Edades salieran a la luz y se manifiestan posteriormente en los textos analizados y en otros que no tienen cabida en este espacio. Sin embargo, nada de ello habría fructificado fuera del seno de la amistad con José Velicia Berzosa. En esa relación fecunda, impregnada de cultura y arte, crecieron y se forjaron las características peculiares Las Edades del Hombre.

\section{AGRADECIMIENTOS}

Agradezco a la Fundación Villalar la concesión de una beca para investigar la historia de Las Edades del Hombre y el apoyo recibido en el Grupo de Investigación en Historia Reciente (GIHRE) de la Universidad de Navarra.

\section{NOTAS}

1 Desde que el músico Joaquín Díaz inició un museo dedicado a instrumentos musicales del folclore castellano, en la localidad vallisoletana de Urueña, esta villa comenzó a convertirse en lugar de cultura tradicional. Actualmente la Junta de Castilla y León la promueve como la ciudad del libro.
2 La fascinación que esta recóndita y peculiar ermita ejerció en Jiménez Lozano se documenta en Guía espiritual de Castilla, pp. 15-23.

3 "La búsqueda y el encuentro de un libro deben ser una aventura tan personal y espiritual como la búsqueda de la iden-

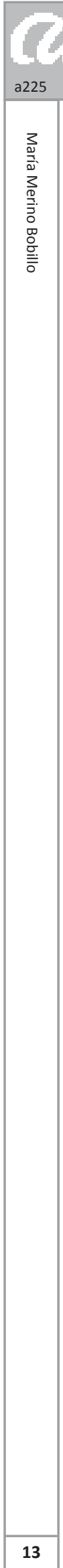

tidad de uno mismo o el hallazgo de una amistad o del amor. Y a su vez, un libro que merezca la pena de tal nombre es también una tal aventura en sí que remite a otros libros y a otros seres humanos y a la memoria histórica colectiva. No se lee impunemente" (Jiménez Lozano, 20 de abril 1983). 


\section{FUENTES}

Entrevistas inéditas realizadas por la autora

Entrevista a José Jiménez Lozano. Alcazarén, 13 de mayo de 2014.

Entrevista a M. a Antonia Virgili Blanquet. Valladolid, 16 de junio de 2010.

Entrevista a Pablo Puente Aparicio. Valladolid, 22 de junio de 2010.

\section{BIBLIOGRAFÍA}

Delibes, M. (1968). Vivir al día. Barcelona: Destino.

Jiménez Lozano, J. (1977, 12 de marzo). Block de Notas. Vida Nueva.

Jiménez Lozano, J. (1977, 19 de septiembre). Las democracias y los monasterios. Informaciones, p. 145.

Jiménez Lozano, J. (1979, 26 de mayo). Block de Notas. Vida Nueva, p. 45.

Jiménez Lozano, J. (1980, 2 de abril). Sobre patrimonio artístico y otras charlatanerías. El País, p. 9.

\section{MATERIAL INÉDITO CONSULTADO EN ARCHIVOS}

Archivo de Pablo Puente Aparicio. Las Edades del Hombre. Presentación.

Archivo de la Fundación Las Edades del Hombre. Las Edades del Hombre. La Iglesia en Castilla y León. Presentación.
Jiménez Lozano, J. (1980, 17 de mayo). Europa y el benedictinismo. El País, p.7.

Jiménez Lozano, J. (1983, 20 de abril). Una fiesta por el libro. Informaciones, p. 2.

Jiménez Lozano, J. (1984). Guía espiritual de Castilla. Valladolid: Ámbito.

Jiménez Lozano, J. (1990). Estampas y Memorias. Madrid: Editorial Infaco.

Ibáñez Ibáñez. J. R. (2005). La escritura reivindicada: Claves interpretativas en los ensayos de José Jiménez Lozano. Valladolid: Junta de Castilla y León.
Laín Corona, G. (2010). Gabriel Miró y el 27. Lecturas e influencias. Revista de Literatura, 72, 144, pp. 397-434.

Martínez Duque, L. (2002). José Velicia, creador y artífice de Las Edades del Hombre. Valladolid: Caja Duero.

Merino Bobillo, M, (2011). Palabras que apuntan lejos. La obra en prensa de José Jiménez Lozano. Madrid: Fragua.

VV.AA. (2002). José Velicia. In memoriam. Valladolid: Caja Duero. 